\title{
Alterações Químicas e Microbiológicas nas Silagens de Capim-Tifton 85 após a Abertura dos Silos
}

\author{
Rúben Pablo Schocken-Iturrino1, Ricardo Andrade Reis², Rogério Marchiori Coan ${ }^{3}$, Thiago \\ Fernandes Bernardes ${ }^{4}$, Rita de Cássia Panizzi ${ }^{5}$, Maria Luiza Poiatti ${ }^{4}$, Márcio dos Santos Pedreira ${ }^{4}$
}

\begin{abstract}
RESUMO - O trabalho foi conduzido para avaliação da presença de Listeria sp. e de fungos nas silagens de capim-Tifton 85 sem emurchecimento, com emurchecimento por uma e duas horas e sem emurchecimento com adição ou não de polpa cítrica (5,0\% do peso verde). As amostragens foram efetuadas no momento da abertura do silo (80 dias da ensilagem), aos 15 e 30 dias após exposição ao ar, para avaliar os teores de matéria seca (MS), as alterações químicas (pH, N amoniacal, ácidos orgânicos) e a ocorrência de Listeria sp. e de fungos. Os dados foram analisados segundo o delineamento em blocos casualizados, em esquema de parcelas subdivididas (nas parcelas foram avaliadas as silagens submetidas aos tratamentos e nas subparcelas, os períodos de exposição ao ar), com quatro repetições. Observaram-se baixos teores de ácidos orgânicos e de $\mathrm{N}$ amoniacal decorrentes dos altos valores de MS, o que acarretou baixa formação de produtos fermentados e elevação do $\mathrm{pH}$. A presença de Listeria sp. foi observada em 65,6\% das amostras no momento da abertura dos silos e, destas, $10 \%$ foram positivas para Listeria monocytogenes. As silagens apresentaram baixa estabilidade aeróbia, tendo sido registrado aumento na ocorrência dos fungos Penicillium, Fusarium e Pithomyces com o prolongamento do período de exposição ao ar.
\end{abstract}

Palavras-chave: bactéria, microbiologia, sanidade animal, silagem de capim

\section{Chemical and Microbiological Changes of Tifton 85 Grass Silage after Silos Opening}

\begin{abstract}
The experiment was carried out to evaluate the fermentation characteristics, Listeria sp. and molds occurrence on Tifton 85 silage no wilted, wilted for one and two hours and no wilted with or without citrus pulp (5.0\% of fresh forage). The samplings were taken at the opening of the silos ( 80 days after ensiling), 15, and 30 days after air exposition to evaluated dry matter (DM) content, chemical changes ( $\mathrm{pH}$, ammonia N, organic acids) and Listeria sp., and molds occurrence. Data were analyzed according to a randomized block design in split plot scheme, considering the silage on the plots, and periods of air exposure on the split plot, with four replications. Low contents of organic acids and ammonia $\mathrm{N}$ due to the high silage DM content that promotes low formation of fermentable products and high $\mathrm{pH}$ values was observed. The occurrence of Listeria sp. was observed in $65.6 \%$ of the silage samples at the opening of the silos and, from them $10 \%$ of these were Listeria monocytogenes. The silages showed poor aerobic stability, having been registered higher amount of Penicillium, Fusarium and Pithomyces occurrence, along the air exposition periods.
\end{abstract}

Key Words: animal health, bacteria, grass silage, microbiology

\section{Introdução}

O processo de ensilagem acarreta profundas modificações na população de microrganismos resultantes das condições anaeróbias dentro do silo, das alterações na pressão osmótica e no $\mathrm{pH}$ da silagem.

A ensilagem de forrageiras com alto conteúdo de matéria seca pode reduzir as perdas inerentes ao processo fermentativo, contudo propicia a produção de silagens com alta instabilidade aeróbia, pois, geralmente, obtém-se forragem com altos valores de $\mathrm{pH}$ e baixos conteúdos de ácidos orgânicos (Woolford, 1984, 1990; McDonald et al., 1991).
A deterioração aeróbia das silagens, além da redução do valor nutritivo, pode aumentar o risco de proliferação de microrganismos potencialmente patogênicos ou daqueles indesejáveis (Driehuis et al., 2001). As leveduras oxidam os ácidos orgânicos que atuam como conservantes, geralmente iniciando o processo de degradação aeróbia e, posteriormente, provocando a elevação do $\mathrm{pH}$ e o desenvolvimento de outros microrganismos, como fungos, Bacillus e Listeria monocytogenes (Woolford, 1990; Driehuis \& Oude Elferink, 2000).

A L. monocytogenes constitui-se de uma célula pequena, móvel, gram positiva, não-esporulada, saprófita que vive no solo, nas plantas e pode ser

\footnotetext{
${ }^{1}$ Professor do Departamento de Patologia, Laboratório de Microbiologia, FCAV/UNESP, Jaboticabal; Bolsista do CNPq (pablo@fcav.unesp.br).

2 Professor do Departamento de Zootecnia, FCAV/UNESP, Jaboticabal; Bolsista do CNPq (rareis@fcav.unesp.br).

${ }^{3}$ Aluno de Doutoramento, FCAV/UNESP, Jaboticabal. Bolsista do CNPq.

${ }^{4}$ Aluno de Doutoramento, FCAV/UNESP, Jaboticabal.

5 Professora do Departamento de Fitossanidade, FCAV/UNESP, Jaboticabal.
} 
encontrada em secreções de animais aparentemente sadios. Pode sobreviver por até dois anos no solo seco e nas fezes e é capaz de crescer sob temperaturas de 4 a $44^{\circ} \mathrm{C}$ (Woolford, 1990).

O desenvolvimento desses microrganismos está diretamente ligado ao $\mathrm{pH}$ da silagem, observando-se inibição do crescimento quando o pH é de 5,2, mas sua perda de viabilidade ocorre somente em $\mathrm{pH}$ mais ácido. Em silagens com $\mathrm{pH}$ elevado, poderá ocorrer desenvolvimento de Listeria, salvo se o teor de matéria seca for muito elevado, em torno de $70 \%$ (Corrot, 1998). Contudo, em algumas situações especiais, foi relatada a ocorrência de Listeria monocytogenes em silagens com pH de 3,8 a pH 4,5 (Ostling \& Lindgren, 1993, Fensterbank et al., 1984, Ryser et al., 1997).

Os fungos, sobretudo as espécies dos gêneros Aspergillus, Fusarium e Penicillium, crescem nos fenos e nas silagens e produzem toxinas que podem acarretar problemas aos animais (McDonald et al., 1991; Mahanna,1994).

A ocorrência de fungos em silagens está associada, principalmente a falhas na compactação, propiciando a entrada de ar no silo, sendo tal fato mais relevante em silagens com alto conteúdo de matéria seca e com tamanho de partículas grandes (Muck \& Shinners, 2001; Pereira \& Reis, 2001).

Os processos de conservação de forragens, como a fenação e a ensilagem, em decorrência das alterações que promovem no conteúdo de matéria seca e no $\mathrm{pH}$ da planta, acarretam mudanças acentuadas na população de microrganismos, havendo diminuição naqueles típicos de campo e aumento na população adaptada às condições do armazenamento (Hlodversson \& Kaspersson, 1986; Mahanna, 1994; Reis et al., 1997).

No presente trabalho, objetivou-se avaliar a ocorrência de Listeria sp. e de fungos e as alterações químicas em silagens de capim-Tifton 85 (Cynodon sp.), em diferentes períodos de exposição ao ar.

\section{Material e Métodos}

O estudo foi conduzido na FCAV/UNESP Campus de Jaboticabal, utilizando o capim-Tifton 85 , cortado no dia 16 de abril de 2001, quando a forrageira estava com 40 dias de crescimento vegetativo, apresentando 10 a $20 \%$ de florescimento e teor médio de matéria seca de $39 \%$.
A forragem foi submetida aos seguintes tratamentos: T1-Tifton ensilado sem pré-emurchecimento; T2 - Tifton ensilado sem pré-emurchecimento e com $5 \%$ de polpa cítrica; T3 - Tifton ensilado com emurchecimento de 1 hora; T4 - Tifton ensilado com emurchecimento de 2 horas. A polpa cítrica peletizada foi adicionada no momento do enchimento dos silos, na proporção de $5 \%$ do peso verde da forragem, e apresentava a seguinte composição bromatológica: $82,24 \%$ de MS, $6,74 \%$ de PB, 23,06\% de FDN e 14,05\% de FDA.

A forragem dos tratamentos sem emurchecimento foi picada em partículas de 3,0 cm, ensilada em silos com capacidade para 200 litros e compactada de forma a possibilitar densidade de $550 \mathrm{~kg} / \mathrm{m}^{3}$. O capim utilizado nos tratamentos com emurchecimento permaneceu no campo, por uma ou duas horas, e, a seguir, foi picado em partículas de 3,0 cm e ensilado, observando os mesmos procedimentos. Os tambores foram armazenados a temperatura ambiente e sob proteção da luz solar e da chuva.

As amostras foram coletadas no momento da abertura dos silos (80 dias após a ensilagem) e aos 15 e 30 dias após a abertura e exposição ao ar. Antes das amostragens, retirou-se uma camada de $5,0 \mathrm{~cm}$ da parte superior dos silos, a fim de se evitar que esta porção mais deteriorada influenciasse os resultados das análises. A seguir, em cada época de amostragem, retiraram-se camadas de $30 \mathrm{~cm}$ de silagem, simulando a utilização de um silo do tipo poço em condições práticas. Após as amostragens nos dias especificados, os silos foram fechados com lona plástica e vedados com tampa metálica a fim de proteger a silagem.

Após a colheita, parte das amostras foram colocadas em estufas de circulação forçada a $65^{\circ} \mathrm{C}$, por 72 horas, para determinação dos teores da matéria seca ao ar, e, em seguida, foram processadas em moinho do tipo Willey com peneira de 30 meshs, para estimação do conteúdo de matéria seca (MS), de acordo com Silva (1990).

Em outra porção da amostra, realizou-se a extração do suco da silagem em prensa hidráulica, para determinação do $\mathrm{pH}$, dos teores de nitrogênio amoniacal, segundo AOAC (1975), e de ácidos orgânicos (ácidos acético, propiônico, lático e butírico) por meio de cromatografia gasosa, de acordo com a técnica de Wilson (1971) modificada por Bonassi, (1977).

O preparo das amostras para análise de Listeria spp. e Listeria monocytogenes consistiu de uma 
diluição prévia, pesando-se $25 \mathrm{~g}$ de silagem (matéria verde) e adicionando-os a $225 \mathrm{ml}$ de solução salina estéril (8,5 g de $\mathrm{NaCl} /$ litro de água destilada). Após agitação, foram retirados $10 \mathrm{~mL}$ do extrato para as diluições posteriores. A partir dos extratos diluídos $\left(10^{-1}\right.$ a $\left.10^{-3}\right)$ foram realizadas as semeaduras no meio Listeria Selective Agar (OXOID), incubandose as placas a $35^{\circ} \mathrm{C}$ por 48 horas. Após a contagem do número de colônias desenvolvidas em cada placa, procedeu-se a semeadura em tubos de cultura contendo infusão de cérebro de coração (BHI DIFCO), incubados a $37^{\circ} \mathrm{C}$ por 24 horas. Após este tempo, foi observado o crescimento da bactéria, realizando-se as seguintes análises: teste de catalase, de motilidade, de nitrato, reação em Agar tríplice açúcar ferro (TSI), teste de verificação de hemólise, teste de fermentação da dextrose, xilose, rhamnose, manitol, maltose e esculina, classificando as espécies de Listeria.

Avaliou-se a ocorrência dos fungos associados ao material ensilado, utilizando-se o método do papel-filtro, usado em testes de sanidade de sementes, adaptado para avaliação da forragem. Foram utilizados dez fragmentos de forragem com $0,5 \mathrm{~cm}$, dispostos em cada placa, de maneira a ficarem eqüidistantes uns dos outros (Lucca Filho, 1987). Esses fragmentos foram incubados sob regime de luz alternada ( 12 horas sob luz e 12 horas no escuro) por sete dias, a uma temperatura de $20 \pm 2{ }^{\circ} \mathrm{C}$. A luz utilizada foi a fluorescente fria e, após o período de incubação, os fragmentos foram examinados individualmente, em microscópio estereoscópio. Sempre que necessário, foram feitas lâminas das estruturas dos fungos, examinando-as em microscópio ótico comum e comparando, segundo Barnett \& Hunter (1972) e Hanlin (1990) para facilitar a identificação. A estimativa de incidência dos fungos foi calculada a partir da fórmula usada por Senthilkumar et al. (1993), determinando-se a porcentagem de ocorrência dosfungos:

Número de amostras em que apareceu o fungo

Porcentagem de freqüência $=-----\times 100$

Número total de amostras examinadas

O delineamento foi inteiramente casualizado, em esquema de parcelas subdividida (nas parcelas, foram avaliadas as silagens submetidas ao emurchecimento, ao uso ou não de polpa cítrica e, nas subparcelas, os períodos de exposição ao ar), com quatro repetições. Os dados foram analisados por intermédio do programa SAS, empregando-se o teste Tukey, para comparação das médias $(\mathrm{P}<0,05)$, de acordo com o seguinte quadro de análise de variância:

\begin{tabular}{lc}
\hline FV & GL \\
\hline Silagens (S) & 3 \\
Erro (a) & 12 \\
Total (parcelas) & 15 \\
Tempo (T) & 2 \\
Interação (SxT) & 6 \\
Erro (b) & 24 \\
Total (subparcelas) & 47
\end{tabular}

$\mathrm{FV}=$ Fontes de variação; $\mathrm{GL}=$ Graus de liberdade . $S V=$ Source of variation; $D F=$ Degrees of freedom .

\section{Resultados e Discussão}

Houve aumento nos conteúdos de matéria seca $(\mathrm{P}<0,05)$ nas silagens, em função da adição de polpa cítrica e do emurchecimento (Tabela 1), o que está relacionado ao alto teor de matéria seca da polpa cítrica $(88,24 \%)$ e da perda de umidade, resultante do processo de emurchecimento pela exposição ao sol.

Apesar de cobrir os silos após a retirada das camadas de $30 \mathrm{~cm}$ de silagem (abertura dos silos, $15 \mathrm{e}$ 30 dias de exposição ao ar), simulando a utilização de um silo poço, este procedimento pode ter influenciado os teores de matéria seca. Deve-se considerar que a retirada apenas da camada superior para a análise, que é mais seca por estar mais exposta ao ar que as camadas inferiores, e também por sofrer a lixiviação de líquidos para a porção inferior dos silos, pode ter resultado em silagem com menor conteúdo de umidade.

As silagens produzidas com forragem que secaram durante uma ou duas horas ao sol atingiram teor de matéria seca de 37,7 e $42,5 \%$ na abertura do silo, 40,7 e $41,1 \%$ aos 15 dias de exposição aeróbia e 56,5 e $58,8 \%$ aos 30 dias, respectivamente.

De acordo com Pereira \& Reis (2001), o ideal para o processo de ensilagem é que a forragem apresente teores de matéria seca de 35 a $45 \%$, sendo que, para valores de 40 a $45 \%$, é recomendável que a forragem seja picada em partículas menores (1,0 a 2,0 cm), a fim de se obter melhor compactação. 
Tabela 1 - Teores de matéria seca (\%), valores de $\mathrm{pH}$, de nitrogênio amoniacal, em relação ao $\mathrm{N}$ total e de ácidos orgânicos (\% MS) das silagens do capim-Tifton 85 submetidas a diferentes tratamentos

Table 1 - Dry matter contents (\%), pH values, ammonia $N$ in relation to total $N$ and organic acids (\% DM) of tifton 85 grass submitted to different treatments

\begin{tabular}{|c|c|c|c|c|c|c|}
\hline \multirow{3}{*}{$\begin{array}{l}\text { Tratamento } \\
\text { Treatment }\end{array}$} & \multicolumn{3}{|c|}{ MS (\%) DM (\%) } & \multicolumn{3}{|c|}{$\mathrm{pH}$} \\
\hline & \multicolumn{3}{|c|}{$\begin{array}{l}\text { Período pós-abertura (dias) } \\
\text { Air exposition period (days) }\end{array}$} & \multicolumn{3}{|c|}{$\begin{array}{l}\text { Período pós-abertura (dias) } \\
\text { Air exposition period (days) }\end{array}$} \\
\hline & 0 & 15 & 30 & 0 & 15 & 30 \\
\hline $\begin{array}{l}\text { Controle (C) } \\
\text { Control (C) }\end{array}$ & $39,1 \mathrm{Bb}$ & $40,70 \mathrm{Bb}$ & $54,6 \mathrm{Ba}$ & $4,7 \mathrm{Ab}$ & $5,0 \mathrm{Bb}$ & $7,2 \mathrm{Ba}$ \\
\hline $\begin{array}{l}\text { Emurchecida ( } 1 \text { hora) } \\
\text { Wilted ( } 1 \text { hour) }\end{array}$ & $37,7 \mathrm{Bb}$ & $40,7 \mathrm{Bb}$ & $56,5 \mathrm{Ba}$ & $4,7 \mathrm{Ab}$ & $4,7 \mathrm{Bb}$ & $6,9 \mathrm{Ba}$ \\
\hline $\begin{array}{l}\text { Emurchecida ( } 2 \text { horas) } \\
\text { Wilted ( } 2 \text { hours) }\end{array}$ & $42,5 \mathrm{Ab}$ & $41,1 \mathrm{Bb}$ & $58,8 \mathrm{Ba}$ & $4,8 \mathrm{Ac}$ & $6,1 \mathrm{Ab}$ & 7,8 Aa \\
\hline $\begin{array}{l}\text { C + Polpa }(5 \% \mathrm{PV}) \\
\text { C + Citrus pulp }(5 \% \text { WB })\end{array}$ & $45,2 \mathrm{Ab}$ & $46,7 \mathrm{Ab}$ & $67,4 \mathrm{Aa}$ & $5,4 \mathrm{Ac}$ & $6,5 \mathrm{Ab}$ & $8,1 \mathrm{Aa}$ \\
\hline $\begin{array}{l}\text { Tratamento } \\
\text { Treatment }\end{array}$ & $\begin{array}{l}\mathrm{N}-\mathrm{NH}_{3} / \mathrm{NT}^{3} \\
\mathrm{TN} / \mathrm{N}-\mathrm{NH}^{3}\end{array}$ & $\begin{array}{l}\text { Lático } \\
\text { Lactic }\end{array}$ & $\begin{array}{l}\text { Acético } \\
\text { Acetic }\end{array}$ & $\begin{array}{l}\text { Propiônico } \\
\text { Propionic }\end{array}$ & $\begin{array}{l}\text { Butírico } \\
\text { Butiric }\end{array}$ & \\
\hline $\begin{array}{l}\text { Controle (C) } \\
\text { Control (C) }\end{array}$ & $7,6 \mathrm{~B}$ & 0,09B & $0,27 \mathrm{~A}$ & $0,02 \mathrm{~A}$ & $0,07 \mathrm{~A}$ & \\
\hline $\begin{array}{l}\text { Emurchecida ( } 1 \text { hora) } \\
\text { Wilted (1 hour) }\end{array}$ & $9,8 \mathrm{~A}$ & $0,08 \mathrm{~B}$ & $0,21 \mathrm{~A}$ & $0,01 \mathrm{~B}$ & $0,05 \mathrm{~B}$ & \\
\hline $\begin{array}{l}\text { Emurchecida ( } 2 \text { horas) } \\
\text { Wilted ( } 2 \text { hours) }\end{array}$ & $8,5 \mathrm{~A}$ & $0,27 \mathrm{~A}$ & $0,28 \mathrm{~A}$ & $0,01 \mathrm{~B}$ & $0,06 \mathrm{AB}$ & \\
\hline $\begin{array}{l}\mathrm{C}+\text { Polpa }(5 \% \mathrm{PV}) \\
C+\text { Citrus pulp }(5 \% \mathrm{WB})\end{array}$ & $4,7 \mathrm{C}$ & $0,02 \mathrm{C}$ & $0,03 \mathrm{~B}$ & $0,01 \mathrm{~B}$ & $0,08 \mathrm{~A}$ & \\
\hline
\end{tabular}

Médias seguidas de mesmas letras, maiúsculas nas colunas e minúsculas nas linhas, não diferem $(P>0,05)$ pelo teste Tukey. Means followed by same letters, capital letters in the columns and lower cases in the lines, do not differ $(P<.05)$ by Tukey test.

Os valores de pH (Tabela 1) foram elevados, evidenciando padrão de fermentação inadequado, o que não é característico de silagens bem conservadas (McDonald et al., 1991). Os elevados valores de $\mathrm{pH}$ (Tabela 1) são decorrentes do alto teor de matéria seca e do tamanho de partícula, que permitiram a entrada de ar nos silos, principalmente no período de exposição ao ar de 15 e 30 dias.

O manejo dos silos, mesmo com o fechamento após a retirada da silagem, pode ter aumentado a instabilidade, mais evidente aos 30 dias de armazenamento quando os valores de $\mathrm{pH}$ variaram de 6,9 a 8,1 (Tabela 1 ).

É importante ressaltar que é possível a preservação da qualidade da forragem ensilada com alto conteúdo de matéria seca com valores de $\mathrm{pH}$ de até 5,0 (Woolford, 1990; Pereira \& Reis 2001).

Cumpre salientar que, de acordo com Woolford (1984) e McDonald et al. (1991), os altos conteúdos de MS da forragem no momento da ensilagem comprometem o processo de fermentação, pois ocorre restrição ao processo fermentativo, em razão da alta pressão osmótica. Dessa forma, em decorrência da ausência de oxigênio, pode-se conservar a forragem com menor influência do pH (Tabela 1).

A análise dos teores de ácidos orgânicos (Tabela 1) evidencia baixos valores, observando-se redução dos conteúdos dos ácidos lático e acético $(\mathrm{P}<0,05)$ com o aumento dos conteúdos de matéria seca, em decorrência do emurchecimento e da adição de polpa cítrica. É importante considerar que, no presente trabalho, registrou-se dificuldade de compactação da silagem em função do elevado conteúdo de MS (Tabela 1), o que acarretou baixa formação de produtos fermentados, entre eles, o ácido lático (Tabela 1), que, em baixas concentrações, tendeu a produzir silagens com altos valores de pH (Tabela 1). Foram observados baixos teores dos ácidos propiônico e butírico nas silagens, não se verificando efeito definido dos conteúdos de MS.

Conforme a literatura, as silagens com alto conteúdo de MS têm como característica baixos conteúdos de ácidos orgânicos e altos valores de $\mathrm{pH}$ (Muck \& Shinners, 2001; Pereira \& Reis, 2001). 
Os valores de $\mathrm{N}$ amoniacal/NT (Tabela 1) diminuíram significativamente com o aumento do conteúdo de matéria seca das silagens emurchecidas e com polpa cítrica. O teor de nitrogênio amoniacal, em relação ao nitrogênio total, é um parâmetro qualitativo da silagem, caracterizado pelo perfil fermentativo ocorrido no processo. Da mesma forma, Pedreira et al. (2001) ensilaram o capim-Tifton 85 e verificaram que o emurchecimento e a adição de polpa cítrica peletizada proporcionaram redução na fração nitrogênio amoniacal.

Menores teores de nitrogênio amoniacal indicam menor intensidade de proteólise durante o processo de fermentação, como resultado da menor atuação de bactérias do gênero Clostridium (McDonald et al., 1991, Muck \& Shinners, 2001). Deve-se considerar ainda que a baixa disponibilidade de água livre dificulta a sobrevivência de microrganismos, principalmente os do gênero Clostridium, que não toleram alto teor de matéria seca e são inibidos, justificando os menores teores de nitrogênio amoniacal e de ácido butírico das silagens com alto conteúdo de MS (Tabela 1).

Woolford (1984) e McDonald et al. (1991), na classificação das silagens quanto ao teor de nitrogênio amoniacal em relação ao nitrogênio total, consideram como: muito boa quando os valores são inferiores a $10 \%$; aceitável de 10 a $15 \%$; e insatisfatória quando os valores se situam acima de $20 \%$.

De acordo com McDonald et al. (1991), uma silagem é considerada de qualidade satisfatória se apresentar $\mathrm{pH}$ inferior a 4,2, teores de ácido butírico menores que $0,2 \%$, na MS, e $\mathrm{N}$ amoniacal inferior ou igual a $11-12 \%$ do $\mathrm{N}$ total. $\mathrm{O} \mathrm{pH}$ ideal para a conservação é dependente da umidade do material e da temperatura, sendo que, em silagens com teor de matéria seca superior a $20 \%$, é aceitável um $\mathrm{pH}$ equivalente a 4,0 para se obter uma conservação satisfatória.

Contudo, apesar das silagens produzidas no presente trabalho apresentarem baixos valores de $\mathrm{N}$ amoniacal e de ácido butírico (Tabela 1), não podem ser consideradas de boa qualidade, sobretudo se forem avaliados os valores de $\mathrm{pH}$ e de ácido lático e a ocorrência de microrganismos que caracterizam os processos fermentativos.

No momento da abertura dos silos observou-se a presença de Listeria sp. (L. monocytogenes, $L$. seeligeri, L. ivannovii, L. innocua, e L. welshimeri) em $65,6 \%$ das amostras de silagem de capim-Tifton 85 (Figura 1). Ressalta-se que $10 \%$ das amostras

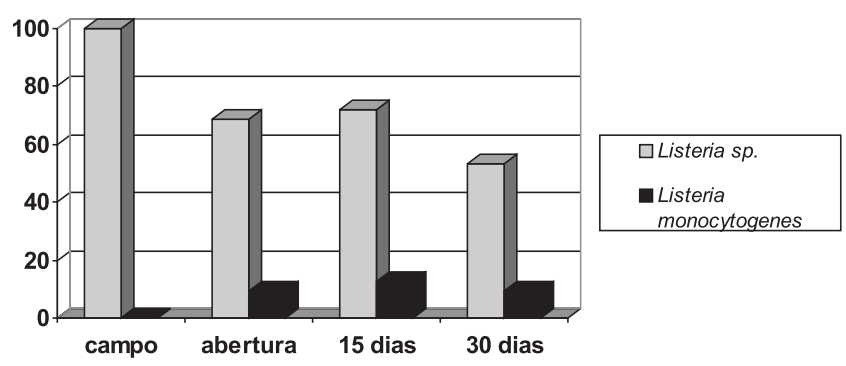

Figura 1 - Ocorrência de Listeria sp. e de Listeria monocytogenes, a partir de colônias típicas isoladas da forragem no campo e das silagens de capim-Tifton 85, avaliadas em diferentes períodos de exposição ao ar.

Figure 1 - Listeria sp. and Listeria monocytogenes occurrence from isolated typical colonies in Tifton 85 forage and silages evaluated in different air exposition periods.

foram positivas para Listeria monocytogenes, que, entre as espécies de Listeria é inquestionavelmente a cepa mais patogênica ao homem e aos animais. Ao contrário da maioria dos patógenos de origem alimentar que geralmente provocam sintomas gastrintestinais, as principais manifestações clínicas da listeriose são inicialmente semelhantes às de um resfriado, com febre baixa e mal-estar geral, podendo progredir para meningite, meningoencefalite, septicemia, aborto ou parto prematuro (Silva et al., 2001). Além disso, essa bactéria pode estar presente no leite cru e nasexcretas de animais contaminados, evidenciando o risco potencial que pode representar para a saúde dos animais e para o homem.

Foi detectada Listeria sp. e Listeria monocytogenes nas silagens colhidas na abertura dos silos, com 15 e 30 dias de exposição ao ar e durante todo o processo de armazenamento. Contudo, não se observou a presença de L. monocytogenes na forragem recém-cortada (Figura 1), indicando que o padrão de fermentação inadequado das silagens com alto conteúdo de matéria seca (Tabelas 1) influenciou a ocorrência desta bactéria. Corrot (1998) relata que, em silagens com alto $\mathrm{pH}$, poderá ocorrer desenvolvimento de Listeria, salvo se o teor de matéria seca for muito elevado, em torno de $70 \%$.

Segundo Fensterbank et al. (1984), a Listeria foi encontrada mais freqüentemente de silagens de baixa qualidade que naquelas de excelente qualidade, embora tenha sido encontrada em 11 das 31 silagens de excelente qualidade, com valores de $\mathrm{pH}$ de 3,6 a 4,0. 
Todavia, Ryser et al. (1997) observaram que 83\%, ou seja, 107 das 129 amostras de silagem de milho de alta qualidade ( $\mathrm{pH} 3,8-4,2)$ avaliadas continham Listeria.

Ostling \& Lindgren (1993) trabalharam com a concentração inibitória mínima de ácido lático nãodissociado, ácidos acético e fórmico nas silagens e avaliaram 23 tipos de enterobactérias e dois tipos de Listeria monocytogenes. O valor da concentração inibitória mínima foi levemente menor em condições anaeróbias, quando comparados com condições aeróbias. Os resultados indicam que os valores de ácido nãodissociados que ocorrem na silagem de $\mathrm{pH} 4,1$ a 4,5 são suficientes para proteger a forragem do crescimento de enterobactérias e Listeria monocytogenes.

Neste estudo, a espécie L. monocytogenes foi identificada na silagem sem desidratação e com $5 \%$ de polpa cítrica em todos os tempos (abertura, 15 e 30 dias após a abertura).

Contudo, a espécie patogênica (L. monocytogenes) não ocorreu no campo, aparecendo somente na silagem em que as condições de pH elevado e baixa concentração de ácidos orgânicos não inibiram o seu desenvolvimento (Figura 1).

O desenvolvimento de bactérias aeróbias, bacilos, coliformes, fungos e leveduras durante a exposição ao ar podem degradar os açúcares residuais e o ácido lático produzidos durante a fase anaeróbia, resultando em aumentos dos valores de $\mathrm{pH}$ e da instabilidade das silagens (McDonald et al., 1991, Driehuis et al., 2001).

Em estudo com silagem de azevém, Fenlon \& Wilson (1998) avaliaram a deterioração aeróbia durante 90 dias, confirmando a relação entre a presença de Listeria monocytogenes e enterobactérias nas silagens deterioradas, indicando que esse último grupo bacteriano pode ser um indicador do risco potencial da contaminação por L. monocytogenes.

Da mesma forma, Pauly et al. (1999) ensilaram gramíneas de clima temperado, Phleum pratense e Dactylis glomerata, submetidas a tratamento mecânico (partícula longa, picada sem condicionamento e picada com condicionamento) e inocularam as forragens com Clostridium tyrobutyricum ou com Listeria monocytogenes, avaliando a forragem no dia da ensilagem, aos 35 e 90 dias de fermentação. Os autores observaram que o condicionamento propiciou maior produção de ácido lático, menores valores de pH e menor ocorrência de Listeria, mas não inibiu o desenvolvimento de Clostridium.
Segundo Driehuis et al. (2001), a aplicação de Lactobacillus buchneri isoladamente ou associado a bactérias láticas elevou a estabilidade aeróbia da silagem de milho, reduzindo a população de leveduras e de fungos.

Em estudo recente, Ranjit et al. (2002) observaram que a adição de L. buchneri aumentou a concentração de ácido acético da silagem de milho, mas reduziu os valores de ácido lático e também a ocorrência de leveduras, propiciando maior estabilidade aeróbia.

A forragem antes da ensilagem apresentou os seguintes gêneros de fungos: Helminthosporium, Nigrospora, Epicoccum, Phoma, Cladosporium,

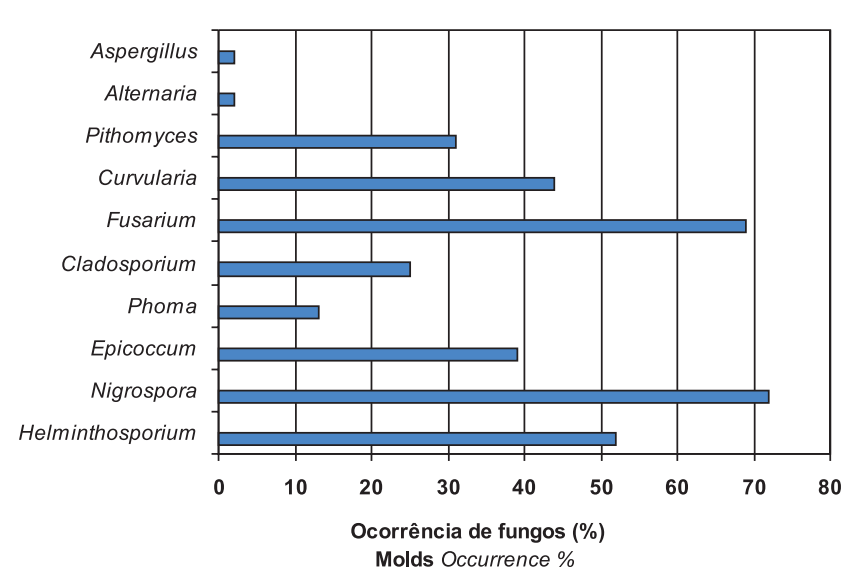

Figura 2 - Gêneros de fungos identificados na forragem de Tifton 85.

Figure 2 - Type of molds identified of Tifton 85 forage

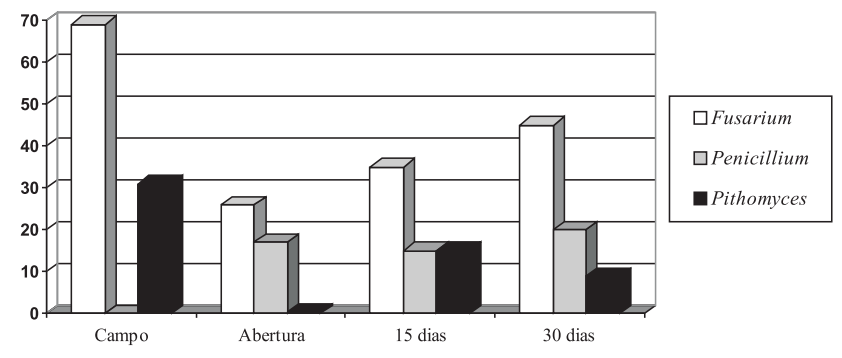

Figura 3 - Ocorrência dos gêneros de fungos identificados em forragem e nas silagens de capimTifton 85, avaliadas em diferentes períodos de aeração.

Figure 3 - Occurrence of molds type identified in the forage and in the grass silages of Tifton 85, evaluated in different aeration periods. 
Fusarium, Curvularia, Pithomyces, Alternaria, Aspergillus. (Figura 2). Todavia, na forragem proveniente do campo, nas silagens colhidas na abertura dos silos e nos períodos de exposição ao ar de 15 e 30 dias, observaram-se incidência dos gêneros patogênicos Fusarium, Pihtomyces, e Penicillium (Figura 3).

De acordo com Hlodversson \& Kaspersson (1986), esses fungos são encontrados em forragem armazenada em condições inadequadas, e de maneira semelhante, Reis et al. (1997) observaram a ocorrência de fungos dos gêneros Cladosporium, Curvularia, Aspergillus e Penicillium nos fenos de grama paulista (Cynodon dactylon (L.) Pers), enfardados com diferentes conteúdos de umidade. Entretanto, segundo esses autores, com o armazenamento durante 30 dias, observou-se diminuição na incidência de Curvularia (fungo de campo) e aumento de Aspergillus e Penicillium, fungos típicos de armazenamento. Os fungos, principalmente as espécies dos gêneros Aspergillus, Fusarium e Penicillium, se desenvolvem em silagens onde há penetração de ar, com formação de toxinas, as quais podem causar doenças aos animais, quando ingeridas (Mahanna, 1994).

$\mathrm{Na}$ abertura dos silos, foi detectada a presença dos gêneros Penicillium e Fusarium, enquanto o gênero Pithomyces apareceu em pequena incidência. Com 15 dias de exposição ao ar, a presença do gênero Pithomyces foi maior nas silagens das plantas submetidas a duas horas de secagem ao sol, portanto com maior teor de matéria seca e pH mais alto (Tabela 1). Contudo, aos 30 dias de exposição ao ar, observou-se a presença de Penicillium e Fusarium, porém o gênero Pithomyces começou a ser detectado nas silagens de plantas que receberam uma hora de sol $(58,8 \%$ de matéria seca e pH de 7,8 ) e aumentou a ocorrência nas silagens de plantas expostas a duas horas de sol $(67,4 \%$ de matéria seca e pH de 8,1) (Tabela 1$)$.

Observou-se nas silagens maior ocorrência de fungos e aquecimento com o prolongamento da exposição ao ar. A presença de oxigênio permitiu o desenvolvimento dos microrganismos tolerantes ao $\mathrm{pH}$ ácido, como os fungos, previamente inibidos pela anaerobiose. Ressalta-se que, durante o desenvolvimento dos fungos, ocorre utilização do ácido lático, resultando em elevação do $\mathrm{pH}$, fato observado nesse estudo (Tabela 1).

De acordo com Driehuis \& Oude Elferink (2000), a deterioração aeróbia de silagens está associada à penetração de oxigênio na forragem durante o armazenamento ou ao fornecimento aos animais. As leveduras que oxidam o lactato geralmente são res- ponsáveis pelo início do processo de deterioração. Posteriormente, atuam fungos, enterobactérias, Bacillus cereus e Listeria motocytogenes, que se desenvolvem na fase aeróbia e representam sério risco para a qualidade das silagens para a saúde dos animais. Na prática, essa deterioração varia entre as diferentes silagens e é geralmente manifestada pela elevação da temperatura, alteração no odor da silagem e pelo aparecimento de mofos (McDonald et al., 1991).

Os fungos mais encontrados em silagens são os do gênero Fusarium, Penicillium e Aspergillus e os principais substratos utilizados pelos microrganismos são os ácidos orgânicos, etanol e os açúcares solúveis residuais, resultando em aumento de $\mathrm{pH}$ e em redução na digestibilidade e do conteúdo de energia (Muck \& Shinners, 2001).

Os elevados teores de matéria seca (Tabela 1), afetados pelo emurchecimento e pela adição de polpa cítrica, contribuíram para elevação do $\mathrm{pH}$, pois propiciaram a baixa formação de ácidos orgânicos, em virtude da dificuldade de compactação encontrada, permitindo desenvolvimento de fungos nas silagens (Figura 3).

Para forragens com elevados teores de matéria seca, recomenda-se que sejam picadas em tamanhos menores e distribuídas em camadas finas, a fim de facilitar a compactação. No presente experimento, o tamanho médio de partícula foi de $3,0 \mathrm{~cm}$ e o teor de matéria seca variou de 39,1 a $45,2 \%$, acarretando dificuldades na compactação dos silos, o que facilitou a entrada de oxigênio na massa ensilada e a presença de fungos.

\section{Conclusões}

As silagens de Tifton 85 apresentaram ocorrência de Listeria sp., Listeria monocytogenes e de vários gêneros de fungos na abertura dos silos e no período de exposição aeróbia de 15 e 30 dias, evidenciando a instabilidade aeróbia decorrente do ineficiente processo de fermentação acarretado pelos altos conteúdos de matéria seca da forragem.

\section{Literatura Citada}

ASSOCIATION OF OFFICIAL AGRICULTURAL CHEMISTS - AOAC. Official methods of analysis. 12.ed. Washington D.C.: Association of Analytical Chemistry, 1975. 109p.

BARNETT, H.L.; HUNTER, B.B. Illustrated genera of imperfect fungi. 3.ed. Burgess: Publishing Company, 1972. 241p. 
BONASSI, I. A. Determinação de ácidos orgânicos em silagens por meio de cromatografia gasosa (Adaptação do método de Wilson, 1971). Jaboticabal: Universidade Estadual Paulista, 1977. 40p. Dissertação (Mestrado em Zootecnia) - Universidade Estadual Paulista, 1977.

CORROT, G. Qualité bacteriologique de l'enrubannage: spores butyriques et Listeria. Recolter \& Conserver L'herbe aujour'hui. Paris: Association Française, 1998. 197p.

DRIEHUIS F.; OUDE ELFERINK, S.J.W.H. The impact of the quality of silage on animal health and food safety: a review. Veterinary Quarterly, v.22, p.212-217, 2000.

DRIEHUIS, F.; OUDE ELFERINK, S.J.W.H.; Van WIKSELAAR, P.G. Fermentation characteristics and aerobic stability of grass silage inoculated with Lactobacillus buchaneri, with or without homofermentative lactic acid bacteria. Grass and Forage Science, v.56, n.4, p.330-343, 2001.

FENLON, D.R.; WILSON, J. The quantitative assessment of Listeria monocytogenes growth in a laboratory ensiling system allowing limited aerobic spoilage. Grass and Forage Science, v.53, n.3, p.292-295, 1998.

FENSTERBANK, R.; AUDURIER, A.; GODU, J. et al. Listeria strains isolated from sick animals and consumed silage. Annual Research Veterinary, v.15, n.1, p.113-118, 1984.

HANLIN, B.T. Illustrated genera of Ascomycetes. St Paul: APS Press, 1990. 263p.

HLODVERSSON, R.; KASPERSSON, A. Nutrient losses during deterioration of hay in relation to changes in biochemical composition and microbial growth. Animal Feed Science, v.15, n.12, p.149-165, 1986.

LUCCA FILHO, O.A. Metodologia de testes de sanidade de sementes. In: Patologia de sementes. Campinas: Fundação Cargill, 1987. p.276-298.

MAHANNA, B. Proper management assures high-quality feeds. Feedstuffs, v.10, p.12-56, 1994.

McDonald, P.; HENDERSON, A.R.; HERON, S.J.E. The biochemistry of silage. 2.ed. Marlow: Chalcombe Publications, 1991. 340p.

MUCK, R.E.; SHINNERS, K.J. Conserved forages (silage and hay): Progress and priorities. In: INTERNACIONAL GRASSLAND CONGRESS, 29., 2001, São Pedro. Proceedings... Piracicaba: Brazilian Society of Animal Husbandry. 2001. p.753-762.

OSTLING, C.E.; LINDGREN, S.E. Inhibition of enterobacteria and Listeria growth by lactic, acetic and formic acids. Journal of Applied Bacteriology, v.75, n.1, p.18-24, 1993.

PAULY, T.M.; HANSSON, J.B.; THAN, W.A. The effect of mechanical forage treatment on the growth of Clostridium tyrobutyricum and Listeria monocytogenes in grass silage. Animal Feed Science and Technology, v.78, p.1127-139, 1999.
PEDREIRA, M.S; MOREIRA, A.L.; REIS, R.A. et al. Características químicas e fermentativas do Tifton 85 (Cynodon) ensilado com diferentes conteúdos de matéria seca e níveis de polpa cítrica. In: REUNIÃO ANUAL DA SOCIEDADE BRASILEIRA DE ZOOTECNIA, 38., 2001, Piracicaba. Anais... Piracicaba: Sociedade Brasileira de Zootecnia, 2001. p.100-102.

PEREIRA, J.R.A.; REIS. R.A. Produção de silagem pré-secada com forrageiras temperadas e tropicais. In: SIMPÓSIO SOBRE PRODUÇÃO E UTILIZAÇÃO DE FORRAGENS CONSERVADAS, Maringá, 2001. Anais... Maringá: Universidade Estadual de Maringá, 2001. p.64-86.

RANJIT, N.K.; TAYLOR, C.C.; KUNG JR., L. Effect of Lactobacillus buchneri 40788 on the fermentation, aerobic stability and nutritive value of maize silage. Grass and Forage Science, v.57, n.2, p.73-81, 2002.

REIS, R.A.; PANIZZI, R.C.; ROSA, B. et al. Efeitos da amonização na ocorrência de fungos, composição química e digestibilidade in vitro de fenos de grama seda (Cynodon dactylon (L.) Pers). Revista Brasileira de Zootecnia, v.26, n.3, p.454-460, 1997.

RYSER, E.T.; ARIMI, S.M.; DONNELLY, C.W. Effects of pH on distribution of listeria ribotypes in corn, hay, and grass silage. Applied Environment Microbiology, v.63, n.9, p.3695-3697, 1997.

SENTHILKUMAR, K.; UDAYAN, K.; MANIAN, S. Successional patern of mycoflora associated with litter degradation in a Cymbopogon caesius dominated tropical grassland. Tropical Grass, v.27, n.27, p.121-127, 1993.

SILVA, D.J. Análise de alimentos: métodos químicos e biológicos. Viçosa, MG: Universidade Federal de Viçosa, 1990. 166p

SILVA, N.; JUNQUEIRA, V.C.A.; SILVEIRA, N.F.A. Manual de métodos de análises microbiológicas de alimentos. 2.ed. São Paulo: Varela, 2001. 295p.

WOOLFORD, M.K. The detrimental effects of air on silage. Journal of Applied Bacteriology, v.68, p.101-116, 1990

WOOLFORD, M.K. The silage fermentation. New York: Marcel Dekker, 1984. 350p. 